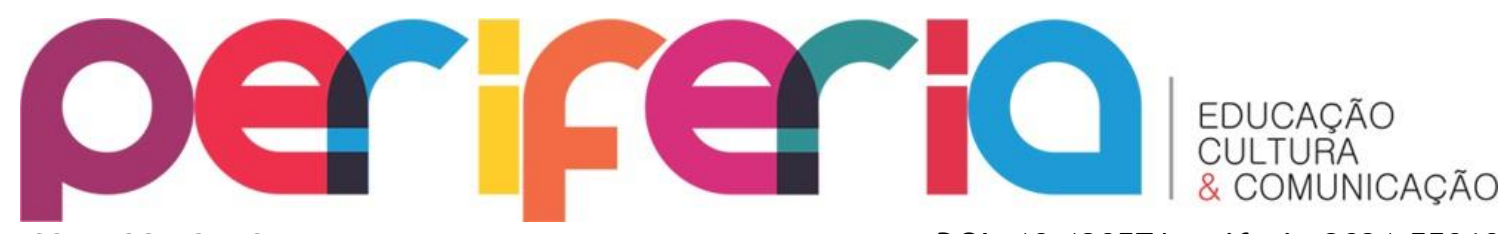

ISSN:1984-9540

DOI: $10.12957 /$ periferia.2021.55960

\title{
POR UMA EDUCAÇÃO QUILOMBOLA: um olhar geográfico à comunidade remanescente Muquém
}

\author{
Thaís Patrícia Paulino da Silva ${ }^{1}$ \\ Marily Oliveira Barbosa²
}

Resumo:

A educação é um direito universal para todo cidadão, independente de etnia e classe social. A educação escolar quilombola vem enfrentando inúmeros desafios ao longo dos anos, pois essa problemática é vestígio da negação histórica da educação para a população negra. Isso decorre de uma configuração socioespacial de como a sociedade brasileira foi formada. 0 presente trabalho tem o objetivo de enfatizar a importância da educação quilombola no campo tendo como recorte espacial a comunidade de remanescente quilombola Muquém, dando ênfase ao currículo quilombola escolar desenvolvido por meio da lei 10.639/2003. A pesquisa participante envolveu alunos do $6^{\circ}, 7^{\circ}$, e $9^{\circ}$ ano da escola do Muquém no estado de Alagoas, diretores e moradores da comunidade. 0 trabalho baseia-se no estudo documental, pesquisa de campo abordando o caráter qualitativo tendo como embasamento teórico Paulo Feire (1987) com sua contribuição sobre a temática da educação no campo para a formação da cidadania. Para melhor aprofundamento foi necessário para coleta de dados aplicação de questionários para alunos e entrevistas a moradores e gestão escolar da comunidade acerca da presença da escola na localidade. Os resultados mostram que através da lei nacional que visa o estudo do ensino da cultura negra brasileira e raízes africanas é com muitos esforços e dedicação que a comunidade vem trabalhando projetos pedagógicos que possibilitem uma nova construção da história do povo negro. Após a enchente de 2010 desenvolveu nos últimos 7 anos um currículo pedagógico que visa os princípios morais como o respeito mútuo, a cidadania e a diversidade.

Palavras-chave: Muquém; Comunidade; Quilombola; Educação.

\footnotetext{
1 Graduada em licenciatura plena em geografia pela Universidade Estadual de Alagoas (UNEAL), integrante do grupo de Estudos Territoriais (GETERRI) e do Grupo de Identidade e Relações Raciais (INVERSO). Atuante na Pastoral da Juventude do Meio Popular (PJMP) no papel de militante e coordenadora nacional representante do Estado de Alagoas. ORCID: https://orcid.org/0000-00025216-7123. E-mail: tatypjmp@gmail.com.

2 Doutora em Educação Especial pela Universidade Federal de São Carlos (UFSCar) - SP, Mestra em Educação pela Universidade Federal de Alagoas (UFAL) - AL, licenciada em Educação Física pela UFAL. Docente do ensino superior no Centro Universitário Maurício de Nassau (UNINASSAU) e pesquisadora do Núcleo de Estudos em Educação e Diversidade (NEEDI) da Universidade Federal de Alagoas (UFAL). Maceió - Alagoas - Brasil. ORCID: https://orcid.org/0000-0001-8189-4234. E-maill: marilyufal@gmail.com
} 


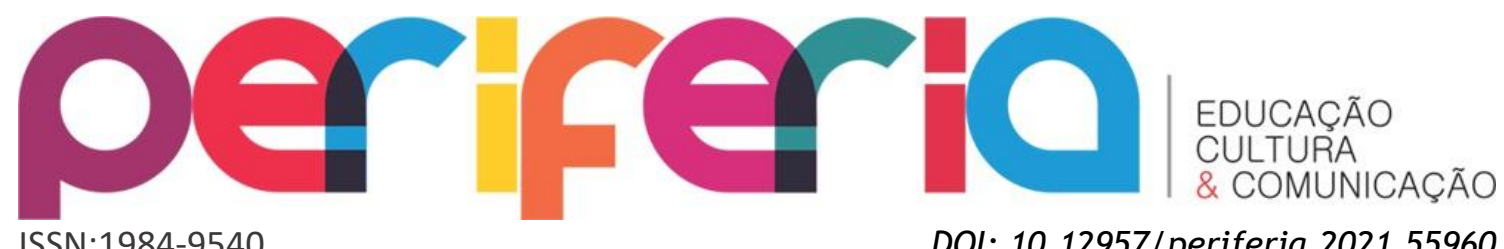

ISSN:1984-9540

DOI: $10.12957 /$ periferia.2021.55960

\section{FOR A QUILOMBOLA EDUCATION: a geographical look at the remaining Muquém community}

\section{Abstract:}

Education is a universal right for every citizen, regardless of ethnicity and social class. Quilombola school education has faced numerous challenges over the years, as this problem is a vestige of the historical denial of education for the black population. This stems from a socio-spatial configuration of how Brazilian society was formed. The present work aims to emphasize the importance of quilombola education in the countryside, having as a spatial cut the community of remnant quilombola Muquém in the state of Alagoas, emphasizing the quilombola school curriculum developed through law 10.639 / 2003. The participating research involved students from the 6th, 7th, and 9th grade of Muquém School, principals, and community residents. The work is based on documentary study, field research addressing the qualitative character having as theoretical basis Paulo Feire (1987) with his contribution on the theme of education in the field for the formation of citizenship. For better deepening, it was necessary to collect data questionnaires application for students and interviews with residents and school management of the community about the presence of the school in the locality. The results show that through the national law that aims to study the teaching of Brazilian black culture and African roots is with many efforts and dedication that the community has been working pedagogical projects that enable a new construction of the history of the black people. After the 2010 flood, over the last 7 years, it has developed a pedagogical curriculum that aims at moral principles such as mutual respect, citizenship and diversity.

Keywords: Quilombola; Community; Muquém; Education.

\section{PARA UNA EDUCACIÓN QUILOMBOLA: una mirada geográfica a la comunidad Muquém restante}

\section{Resumen:}

La educación es un derecho universal para todos los ciudadanos, independientemente de su origen étnico y clase social. La educación escolar quilombola ha enfrentado numerosos desafíos a lo largo de los años, ya que este problema es un vestigio de la negación histórica de la educación a la población negra. Esto se deriva de una configuración socioespacial de cómo se formó la sociedad 


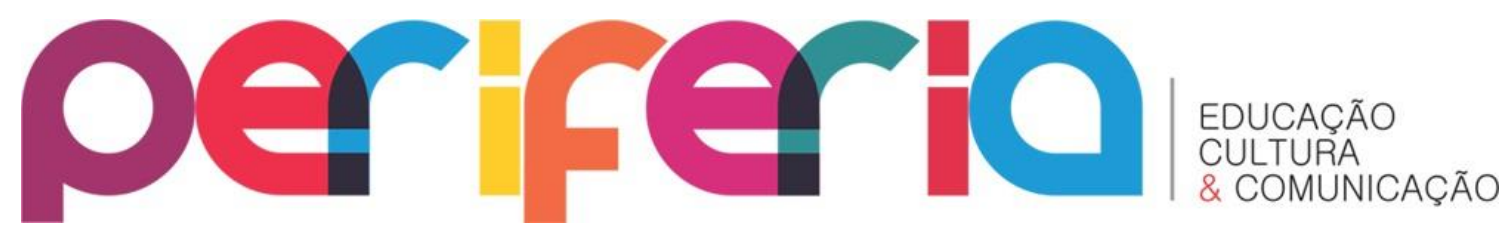

ISSN:1984-9540

DOI: $10.12957 /$ periferia. 2021.55960

brasileña. El presente trabajo tiene el objetivo de enfatizar la importancia de la educación quilombola en el campo teniendo como espacio espacial la comunidad del remanente quilombola Muquém en el estado de Alagoas, enfatizando el currículo escolar quilombola desarrollado por la ley 10.639 / 2003. La investigación participante involucró a estudiantes de $6^{\circ}, 7^{\circ}$ y $9^{\circ}$ grado de la escuela Muquém, directores y residentes de la comunidad. El trabajo se basa en el estudio documental, investigación de campo que aborda el carácter cualitativo que tiene como base teórica a Paulo Feire (1987) con su aporte sobre el tema de la educación en el campo de la formación de la ciudadanía. Para un mejor entendimiento, fue necesario recolectar datos, aplicación de cuestionarios a los estudiantes y entrevistas con los residentes y la dirección escolar de la comunidad sobre la presencia de la escuela en la localidad. Los resultados muestran que a través de la ley nacional que tiene como objetivo estudiar la enseñanza de la cultura negra brasileña y las raíces africanas, es con mucho esfuerzo y dedicación que la comunidad ha venido trabajando en proyectos pedagógicos que permitan una nueva construcción de la historia de los negros. Después de la inundación de 2010, en los últimos 7 años, desarrolló un plan de estudios pedagógico que apunta a principios morales como el respeto mutuo, la ciudadanía y la diversidad.

Palabras clave: Muquém; Comunidad; Quilombola; Educación.

\section{INTRODUÇÃO}

Falar em educação no Brasil é tratar de uns dos maiores direitos de qualquer cidadão, mas o que enxergamos na realidade em que vivemos é esse direito sendo negligenciado pelo grande Estado por meio desse modelo ideológico e político do sistema capitalista que tendem a não priorizar os direitos do cidadão para a construção da sua cidadania. Esta é mutilada todo dia, pois são retirados os direitos dos pobres e dando privilégios para a burguesia, como dizia Milton Santos (1997). Sendo a educação um dos direitos universais - que deveria ser ofertada a todos com equidade - quando nos referimos a educação camponesa, percebemos que é a mais prejudicada com a falta de investimentos por parte do governo para que os filhos de camponeses, povos tradicionais, negros e indígenas possam estudar garantindo seu direito de frequentar uma escola pública e de qualidade.

A educação no campo foi uma conquista que durou décadas para ser alcançada, logo entender esse processo que perdurou séculos é muito importante 


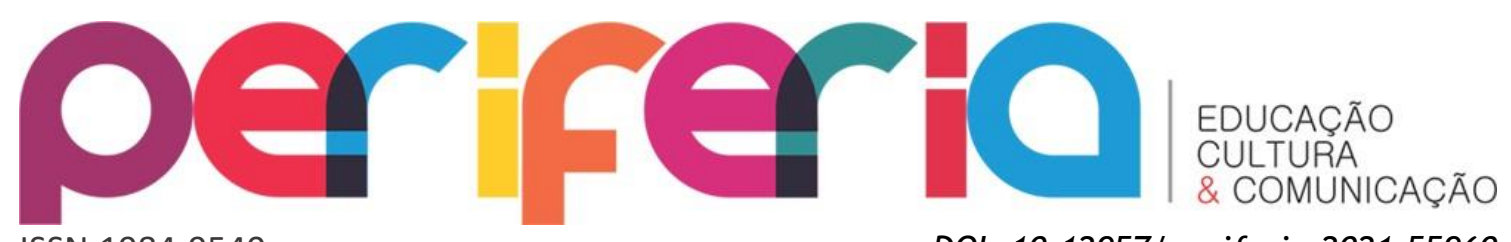

ISSN:1984-9540

DOI: $10.12957 /$ periferia. 2021.55960

para analisar como se desenvolve a educação no campo hoje. Quando nos referimos à educação na área rural até os dias de hoje houve pouca evolução no campo, pois o modelo de educação é muito superficial, e não condiz de fato com a realidade vivida por camponeses, ribeirinhos, indígenas e quilombolas.

Segundo o Decreto de $n^{\circ} 7.352$ de 4 de novembro de 2010 são consideradas população do campo: agricultores de família, extrativistas, pescadores artesanais, ribeirinhos, assentados e acampados da reforma agrária, trabalhadores assalariados rurais, quilombolas, caiçaras, povos da floresta, caboclos e todos aqueles que vivem no campo e produzem seu trabalho e vida a partir do meio rural (BRASIL, 2010).

Para Caldart (2009) a educação no campo pode ser analisada por três caminhos: o primeiro é sobre a constituição originária que se liga à prática da educação no campo; segundo, trata-se de apreender quais tensões e enxergar as contradições existente no meio rural; e o terceiro, diz respeito a pensar nas ações políticas urgentes e os esforços de identificar quais os desafios, os empasses que permeiam a educação no campo.

Nesse viés, é importante fazermos uma análise para compreender como se desenvolveu/desenvolve o ensino dentro de uma comunidade tradicional no campo em meio a todo processo perverso do sistema capitalista pois, para Freire (1987), o modelo de educação que temos é um perfil que segue as classes dominantes. Tal modelo ele denominou educação bancária que condiz a um ensino hierarquizado, reprodutor, não-crítico.

Diante disso, Freire (1987) propõe uma nova concepção de educação voltada para a problematização, na qual não exista hierarquia do ensino e sim a possibilidade de aprender para a libertação e obter uma consciência de classe. Contudo, a educação é uma importante ferramenta para a libertação coletiva dos indivíduos para que não nos tornemos massa de manobra do sistema e sim sujeitos críticos, capazes de transformar a realidade e lutar a favor dos oprimidos.

Nesse contexto, o presente trabalho tem o objetivo de enfatizar a importância da educação quilombola no campo tendo como recorte espacial a comunidade de remanescente quilombola Muquém, dando ênfase ao currículo quilombola escolar desenvolvido por meio da lei 10.639/2003, Tendo como objeto de estudo a Escola e as práticas de ensino e aprendizagem, com base no currículo 


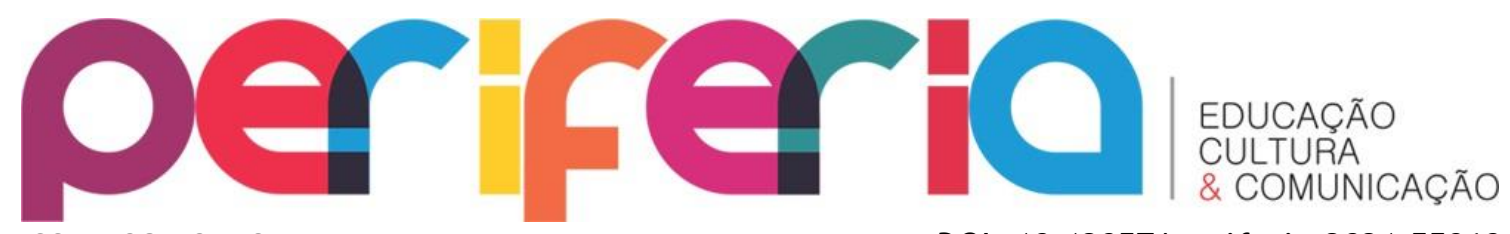

ISSN:1984-9540

DOI: $10.12957 /$ periferia. 2021.55960

escolar quilombola, de acordo com a lei 10.639/2003 e a lei Municipal do $n^{\circ}$ 994/03 de 12 de março de 2003 que auxilia no estudo da história palmarina na rede municipal de ensino da cidade (BRASIL, 2003; UNIÃO DOS PALMARES, 2003). A pesquisa visa enfatizar a importância da escola na comunidade quilombola Muquém, buscando entender como se desenvolve o currículo quilombola e como as crianças que estudam na comunidade a enxergam, visto que foi uma conquista da comunidade, pois atua também como um espaço de formação e resgate das tradições históricas e atividades culturais do povoado.

A principal categoria geográfica escolhida para análise da pesquisa é o lugar, tendo em vista que este é umas das categorias mais importantes da geografia para trabalhar a relação de identidade e pertencimento, pois é no lugar que podemos perceber o movimento do mundo onde as coisas se materializam e criam possibilidades, desse modo, o lugar traz simbolismo, sentimentos e ações que contribuem para o processo de identidades gerada a partir das particularidades das relações sociais no território. Dessa forma, segundo Milton Santos o lugar é a quinta Parte do cotidiano das relações criadas dentro do espaço geográfico, (SANTOS, 2012).

\section{PROCEDIMENTO METODOLÓGICO}

O Método é o caminho para o desenvolvimento de qualquer pesquisa, pois possibilita mecanismos de análises do objeto de estudo. É através do método que o pesquisador pode definir a sua linha de pesquisa. 0 método escolhido para a referida pesquisa foi o materialismo histórico-dialético por acreditar que é a melhor forma de investigação do objeto de estudo da educação quilombola. Enxergar a sociedade de forma dialética é importante, pois percebemos a totalidade das coisas, seu dinamismo e movimento.

De acordo com Lakatos e Marconi (2003), o materialismo histórico como método de análise marxista nos faz retornar ao passado para compreender os acontecimentos atuais e as transformações que a sociedade sofre por meio de um jogo dialético das relações sócio-culturais. Por isso se faz necessário:

[...] investigar acontecimentos, processos e instituições do passado para verificar a sua influência na sociedade de hoje, pois as instituições 


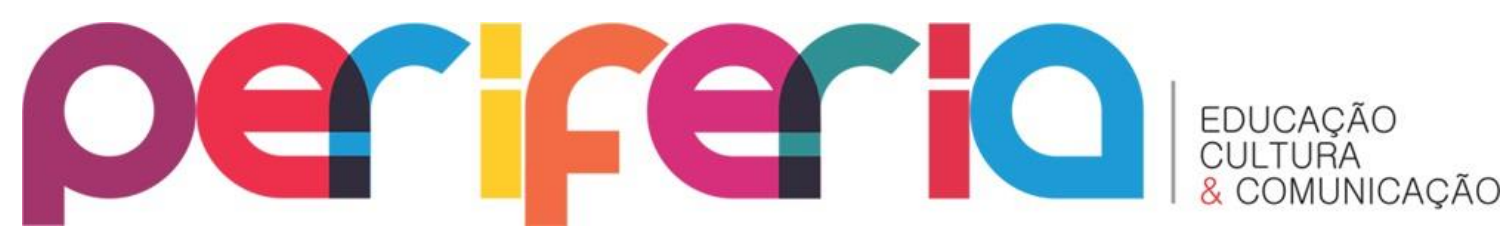

ISSN:1984-9540

DOI: $10.12957 /$ periferia. 2021.55960

alcançaram sua forma atual através de alterações de suas partes componentes, ao longo do tempo, influenciadas pelo contexto cultural particular de cada época. Seu estudo, para uma melhor compreensão do papel que atualmente desempenha na sociedade, deve remontar aos períodos de sua formação e de suas modificações (LAKATOS; MARCONI, 2003, p.107).

O conceito utilizado na pesquisa é o conceito de território usado do professor Milton Santos, no qual visa o território como uma totalidade chamada espaço geográfico que é usado por todos os agentes que são responsáveis em dar funcionalidade ao território, criando objetos e ações que norteiam a vida (SANTOS, 2012). E em conjunto ao conceito de território usado, buscamos entender o lugar em que vivemos, a categoria de análise desse trabalho é o lugar, sinônimo de afetividade e identidade de simbologia, entender o lugar nos permite também ter uma visão do mundo a partir de onde estamos, pois é no lugar que o movimento mundo é percebido. $\mathrm{E}$ por isso, deve ser objeto de interesse dos geógrafos a quem cabe forjar os instrumentos correspondentes de análise.

0 método escolhido para a referente pesquisa foi o método materialismo histórico -dialético tendo em vista que esse caminho é capaz de responder e dar suporte para o trabalho, pois, é capaz de auxiliar no estudo e análise do objeto de estudo interferindo na realidade de forma dialética. De modo que vivemos em um mundo confuso e confusamente percebido que se transforma a cada novo objeto inserido na sociedade e os homens também se transformam na medida do processo que as coisas evoluem e o método capaz de responder ou dar mecanismos de entendimento a todas essas mudanças na sociedade é a dialética (KONDER, 2004).

Para explicar sobre o método dialético foi desenvolvido três leis que norteiam o pesquisador (KONDER, 2004). A primeira lei se refere ao fato de que, ao mudarem, as coisas não mudam sempre no mesmo ritmo - o processo de transformação por meio do qual elas existem passa por períodos lentos (nos quais se sucedem pequenas alterações quantitativas) e por períodos de aceleração (que precipitam alterações quantitativas, isto é, "saltos", modificações radicais). A segunda lei é aquela que nos lembra que tudo tem a ver com tudo, ou seja, os diversos aspectos da realidade se entrelaçam e, em diferentes níveis, dependem uns dos outros, de modo que as coisas não podem ser compreendidas isoladamente. A terceira lei dá conta do fato 


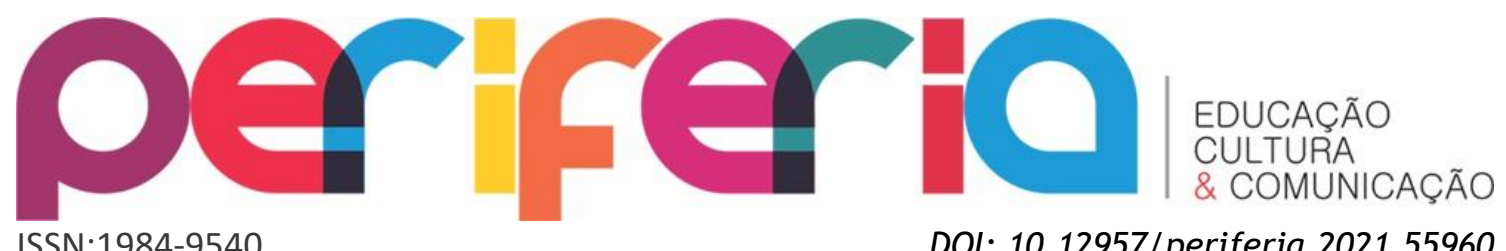

de que o movimento geral da realidade faz sentido, quer dizer, não é absurdo, não se esgota em contradições irracionais, ininteligíveis, nem se perde na eterna repetição do conflito entre tese e antíteses, entre afirmações e negações.

Segundo Prodanov e Freitas (2013) a metodologia é importante, pois dá estratégias que possibilitam um maior aprofundamento acerca do objeto pesquisado de modo que auxilia em etapas que darão suporte para os resultados finais. Dessa forma, a pesquisa está embasada nas categorias de análise de lugar e território. Para auxiliar no trabalho foi preciso a ida a campo para melhor compreender o objeto de estudo; na ida à comunidade Quilombola Muquém visitamos a escola onde foi proposta a aplicação de questionários para 65 alunos da Escola de Ensino Municipal Pedro Pereira da Silva para estudantes do $6^{\circ}, 7^{\circ}$ e $9^{\circ}$ ano do Ensino Fundamental II, sendo 21 do $6^{\circ}, 19$ do $7^{\circ}$ e 25 do $9^{\circ}$ ano. Foram realizadas entrevistas com 10 moradores entre eles representantes da associação de moradores, 2 gestores da Escola. No total, participaram da pesquisa 77 pessoas incluindo as crianças da escola. A observação do campo foi realizada durante três (3) dias, nos quais a metodologia foi dividida em 4 etapas: primeira, foi composta por pesquisas bibliográficas, incluindo também leituras do Estatuto igualdade racial para melhor desenvolvimento do referente trabalho; segunda, visita e fotos da comunidade, terceira entrevistas aos representantes da associação de moradores da comunidade, E a quarta e última etapa foi aplicação de questionários às crianças da escola do Muquém.

\section{O SER QUILOMBOLA E A CIDADANIA}

De acordo com o Instituto Nacional de Colonização e Reforma Agrária - INCRA comunidades quilombolas são grupos étnicos predominantemente constituídos pela população negra rural ou urbana que se autoafirma a partir das relações específicas como o território, o parentesco, a terra, a ancestralidade, as tradições ou práticas culturais particulares. Estima-se que em todo território brasileiro existam mais de 3 mil comunidades de quilombos.

O termo comunidade Quilombola é um conceito político-Jurídico que tenta dar conta de uma realidade extremamente complexa e diversa que implica na 


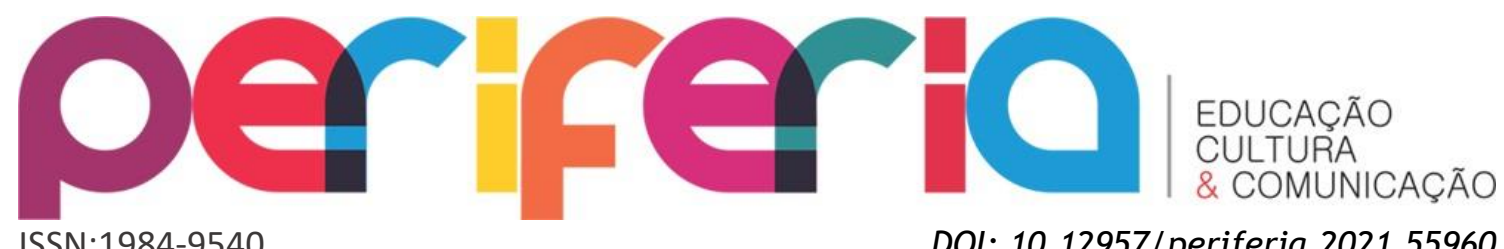

valorização de nossa memória e no reconhecimento da dívida histórica que o Estado nacional tem para com o população negra (FCP, 2020).

A constituição federal de 1988 reconhece e protege os direitos sociais, culturais econômicos e políticos dos remanescentes de comunidades quilombolas. Os Artigos 215 e 216 e o Ato das Disposições Constitucionais Tradicionais que tratam desses direitos. [...] são considerados remanescentes de comunidades quilombolas dos grupos étnico-raciais, segundo critérios de auto-atribuição, com trajetória histórica específicas, com presunção de ancestralidade negra relacionada com a resistência à opressão histórica sofrida (REIS, 2014, p.5).

Conforme o art. $2^{\circ}$ do Decreto $n^{\circ} 4.887$, de 20 de novembro de 2003, considera que remanescente de quilombos são grupos étnico - raciais com uma trajetória ligada à relação com o território e com a cultura negra, portanto essas comunidades devem ser protegidas e asseguradas de direitos pelo Estado (BRASIL, 2003).

A Fundação Cultural Palmares criada em 1988, pela Lei de $n^{\circ} 7.668$ (REIS, 2014), tendo vínculo com o Ministério da cultura, tem a função de promover a preservação dos direitos do povo quilombola do Brasil, além de acompanhar, fiscalizar e incentivar as ações econômicas, culturais e sociais dos remanescentes.

Assim, como todo indivíduo, o povo quilombola também têm seus direitos de cidadão que devem ser garantidos pelo Estado. A cidadania parte da necessidade mais que social de cunho jurídico do que cultural, pois é papel do governo assegurar que todos tenham de forma igualitária os direitos à saúde, moradia, segurança e educação. Porém, o que se percebe na prática é uma desigualdade perversa do sistema em que os diretos são negligenciados para os pobres e incluindo à essa classe pobre trabalhadora estão os quilombolas, camponeses, indígenas e ribeirinhos.

Mas o que percebemos, segundo Milton Santos (2014), é que a nossa cidadania é mutilada todo os dias, pois o que existe é uma divisão de classes em que uma é privilegiada e à outra são negados seus direitos. De fato, nunca houve essa cidadania para todos. E quando nos referimos ao povo negro, foram eles que mais sofreram e sofrem com essa perversidade sistêmica em que, até os dias atuais, a nossa sociedade segue. Por isso, Milton Santos nos faz refletir quando fala que, de fato, nunca houve cidadão no Brasil. 


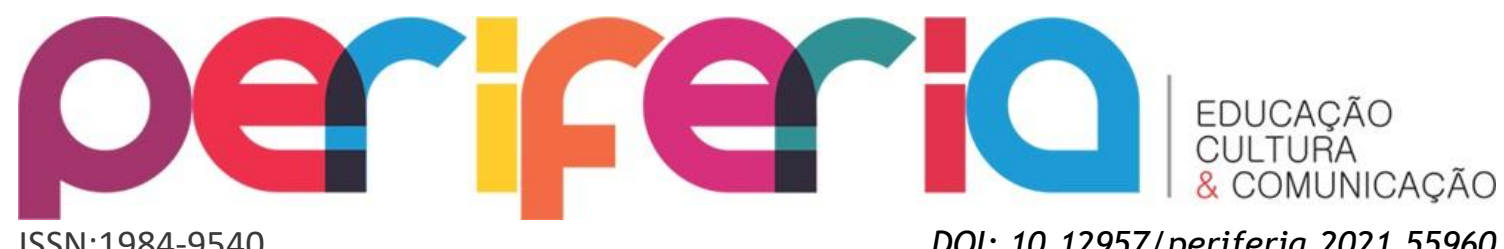

Em nosso país jamais houve a figura do cidadão. As classes chamadas superiores, as classes médias; jamais quiseram ser cidadãs, os pobres jamais puderam ser cidadãos. As classes médias foram condicionadas a apenas querer privilégios e não direitos. (SANTOS, 1997, p.134).

\section{A EDUCAÇÃO CAMPONESA- QUILOMBOLA E SEUS DESAFIOS.}

É notório que, dentre os conjuntos primordiais de direitos, o direito à educação é essencial para a formação da cidadania do ser. A educação nos permite enxergar e entender o mundo e as coisas como elas são e se colocar dentro desse universo tão complexo e cheio de mistérios para desvendar. Todos têm o direito à educação.

A educação é por sua natureza ontológica, uma mediação para a produção da totalidade social, isto é, ela é quem medeia a transformação do mundo natural em fins sociais [...] (MOREIRA; MACENO, 2012, p. 181).

Segundo Bezerra (2017), no decorrer da história da educação no Brasil o direito à escola foi negado ao negro e a universalização da educação popular é um processo lento ao longo do tempo se tornando uma dívida social até os dias de hoje. A autora afirma que a história da educação brasileira tem como balizadora a formação de uma sociedade dualista que decorre de séculos de escravidão e que se desdobra para além desse período.

Tratando-se do direito sobre a educação no Brasil o Eca - Estatuto da Criança e do Adolescente, traz em seu Artigo de $\mathrm{n}^{\circ} 53^{\circ}$ que crianças e adolescentes tem o direito à educação, visando seu desenvolvimento pessoal, preparação para o exercício da cidadania e qualificação para o trabalho (BRASIL, 2016, p.42).

A escola é um espaço de formação política e social dos indivíduos, ao mesmo tempo que esta possui como função humana a socialização dos saberes acumulados e os processos de construção e reelaboração dos conhecimentos que o homem ao longo do tempo e do espaço constrói. Portanto, para aquelas pessoas que vivem no campo, a escola também representa um espaço de luta.

Para Machado (2011), quando abordamos a questão dos eventos históricos da educação rural. A educação do campo, as concepções de escola e de educadores são fundamentais para a compreensão de qual modelo de educação foi ofertada aos 


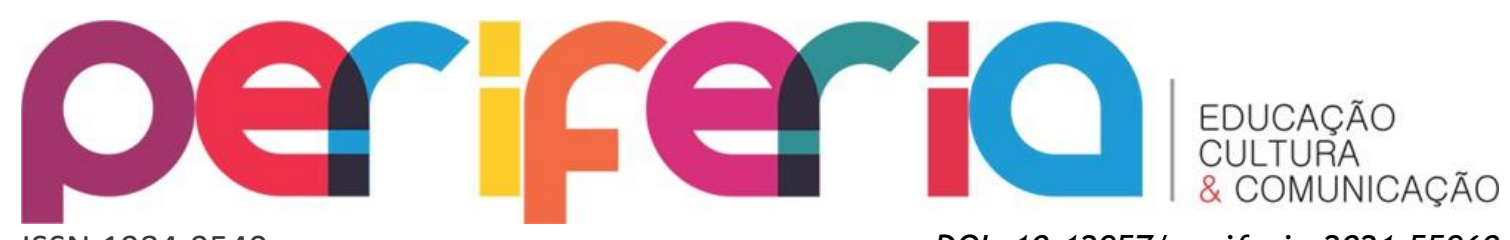

ISSN:1984-9540

DOI: $10.12957 /$ periferia.2021.55960

povos moradores de áreas não urbanas. Por conta disso, os educadores são sujeitos importantes para a construção de uma sociedade mais humanizada e justa.

Para Freire (1987) a educação no campo deve ser uma educação problematizadora, isto é, aquela que liberta, que enxerga os educandos como protagonistas da sua história, como transformadores do mundo e não apenas um expectador dele, mas como aqueles que pertencem ao mundo e que através de suas ações moldam as coisas e o mundo. É aquela que forma os educandos para a vida, trabalhando com a problematização das estruturas das coisas, pelo qual o educador não é ditador, mas formador, pois não é dono do saber e sim compartilhador deste.

A libertação do homem é uma ação social e não pode ser conquistada isoladamente. 0 homem é um ser social, dessa forma, a transformação do meio deve ser um acontecer homólogo, horizontal em sociedade. É a educação a principal ferramenta para a liberdade dos indivíduos, sejam eles do campo ou da cidade. É por meio da educação e do ensino (escola) que percebemos as perversidades do sistema e deixamos de ser alienados por ele.

Quando pensamos em uma escola de caráter quilombola trabalhamos com os temas transversais conforme descrito nos PCNS. Eles visam uma educação que prepare para a cidadania com princípios orientadores voltados à dignidade humana. Ainda segundo os PCNS, não é interessante trabalhar apenas as disciplinas tradicionais, por isso a necessidade dos temas transversais que entre eles envolve trabalhar dentro da educação a ética e a pluralidade cultural.

Trabalhar a pluralidade dentro do ambiente escolar é entender que vivemos em uma sociedade plural e não homogênea, pois somos formados por índios, negros e brancos. A escola tem esse desafio de ensinar sobre essa diversidade cultural, mas não se limitar apenas a conceitos e sim promover o respeito mútuo entre as culturas, explorando a riqueza ética do Brasil. Visto assim, isso não deve se dar de forma isolada, mas em conjunto com toda a comunidade escolar.

A BNCC é um importante documento que norteia o ensino básico brasileiro, uma orientação curricular que oferece uma referência para a elaboração do currículo e adequação do planejamento pedagógico.

A BNCC estrutura os conteúdos de acordo com cada ano e componente curricular, ela direciona e traz detalhamentos sobre cada conteúdo e seu respectivo 


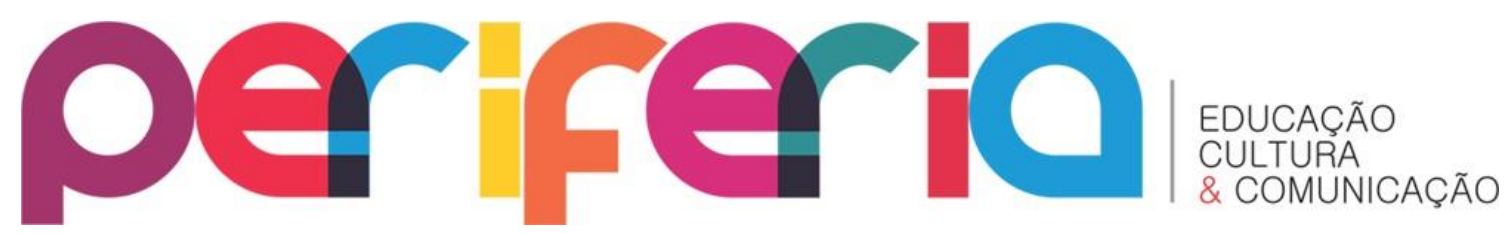

ISSN:1984-9540

DOI: $10.12957 /$ periferia.2021.55960

nível de atuação. É um documento obrigatório para toda rede de ensino que visa acabar com as desigualdades na busca de uma equidade para a Educação Básica no Brasil em integração com as três esferas: nacional, estadual e municipal. Conforme a parte introdutória do documento,

[...] A BNCC trata-se da implementação de uma política nacional articulada e integrada em parceria com o MEC e com os Estados [...], para adequação do ensino ou seja ela é um documento valioso para a educação. Ela tem [...] caráter normativo que define o conjunto orgânico e progressivo de aprendizagem essenciais que todos alunos devem desenvolver ao longo das etapas e modalidades da educação básica [...]. ( BRASIL, 2019, p .7).

\section{A COMUNIDADE QUILOMBOLA MUQUÉM}

A comunidade quilombola Muquém é um povoado de remanescentes do Quilombo dos Palmares, localizado na zona da mata do Estado de Alagoas, na mesorregião imediata de União dos Palmares-AL, (IBGE 2010). Esse povoado está à $5 \mathrm{~km}$ do município palmarino, nas margens da bacia hidrográfica do Rio Mundaú, sendo uma das 70 Comunidades reconhecidas de remanescentes quilombolas do Estado de Alagoas. 


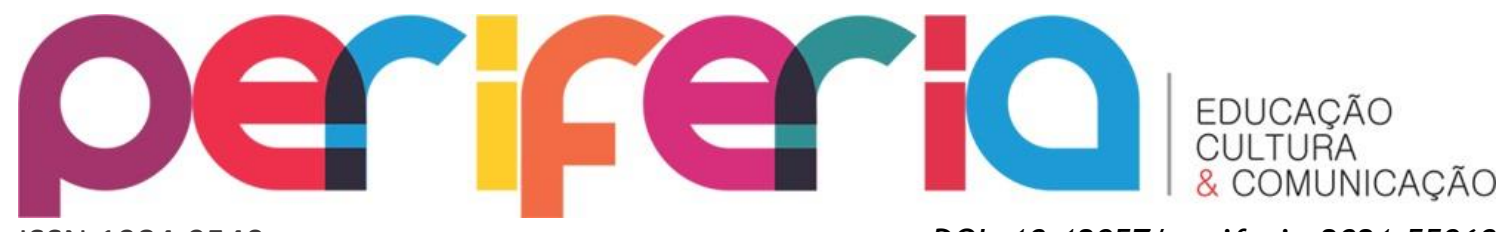

Figura 1: Mapa das Comunidades Quilombolas de Alagoas.

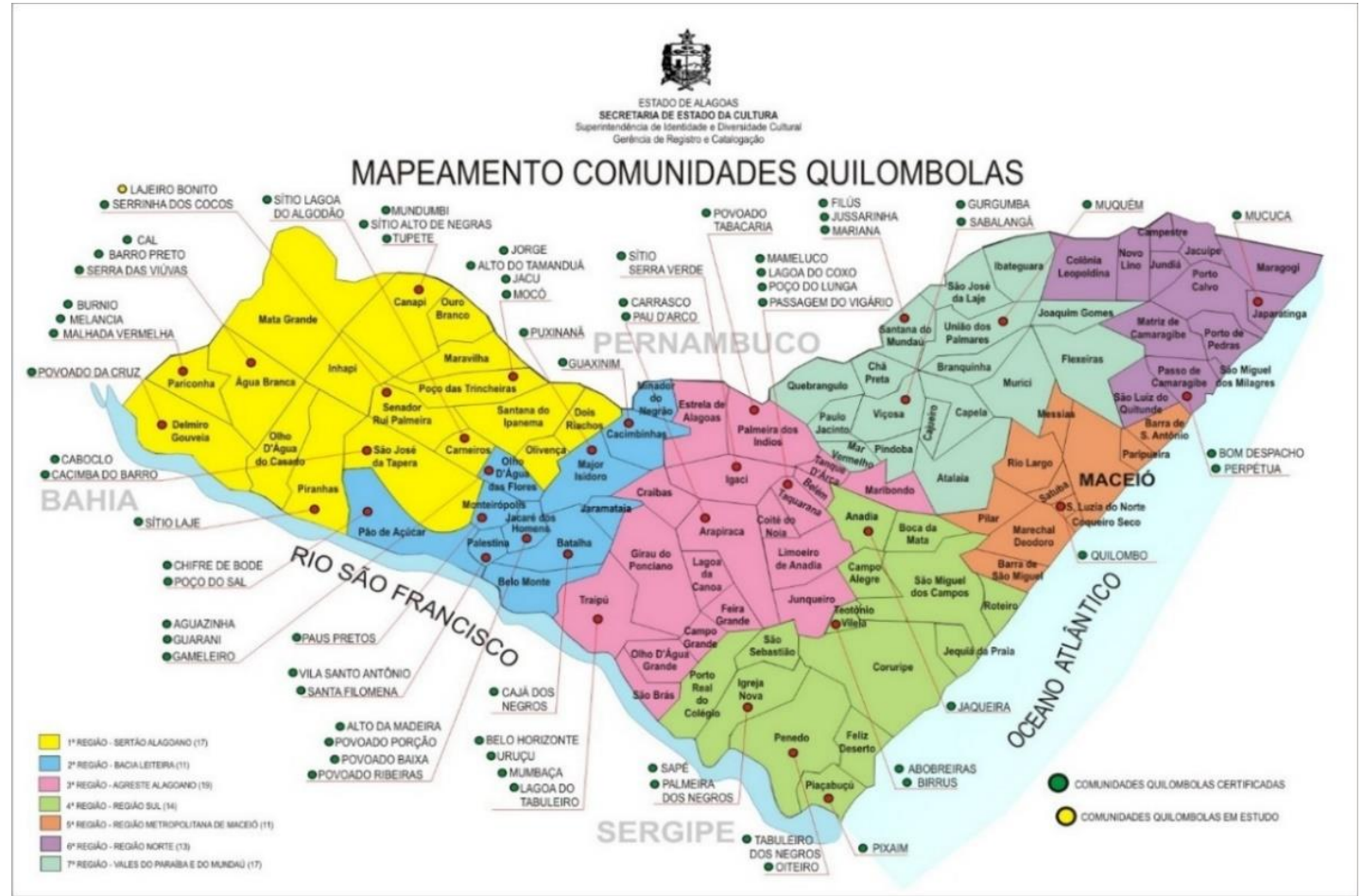

Fonte: ALAGOAS,2020

Segundo os mais velhos moradores da comunidade, o Muquém surgiu dos sobreviventes do massacre de Palmares, em 6 de fevereiro de 1694. Afirmaram ainda que a comunidade tem o nome Muquém originado do povo bantu que significa se esconder ou escondido. A comunidade foi fundada por um casal, Maria Camila da Conceição Nunes e Leopodino Bezerra da Silva, os primeiros negros quilombolas, foram eles que povoaram todo o Muquém. Desde seus ancestrais até hoje o povoado trabalha com o artesanato da cerâmica, tendo como matéria prima o barro e a argila. Os quilombolas sobrevivem do artesanato, da agricultura de subsistência, dos programas do governo federal (Bolsa Família e aposentadoria) e do turismo. A comunidade foi titulada em 2005, com o reconhecimento do INCRA como área de território quilombola.

Atualmente o povoado tem 167 famílias, com a população total de 767 quilombolas. 0 conjunto principal chamado Muquém Novo tem 120 casas feitas pelo governo federal - construídas após a enchente de 2010, que atingiu toda a comunidade e outros povoados e bairros da cidade de União dos Palmares, em 18 de 


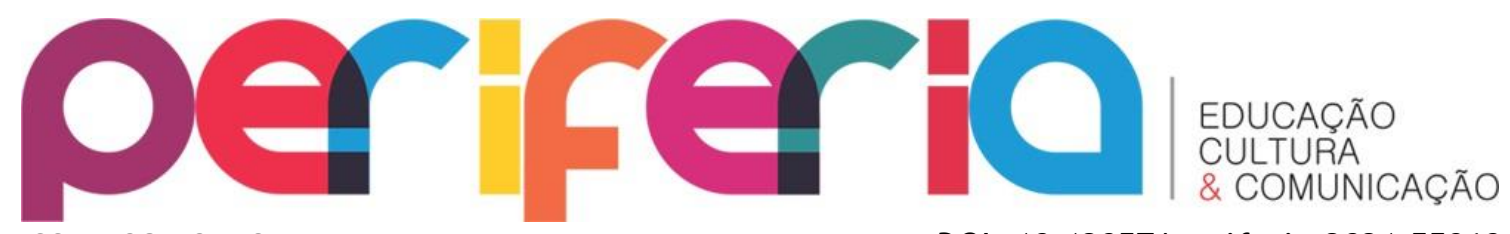

ISSN:1984-9540

DOI: $10.12957 /$ periferia. 2021.55960

junho de 2010, desabrigando quase toda a comunidade. No ano de 2012 a 2013 foram entregues as casas do governo aos quilombolas.

$\mathrm{Na}$ nova configuração espacial do novo Muquém foram criados espaços como o galpão do artesanato local em que é exposto todo o artesanato do povoado para que visitantes e turistas possam conhecer o principal fator da história do Muquém: o artesanato de barro. Também foi construído o Espaço Cultural que é um lugar para festas, reuniões, aulas de capoeira e dança afro; espaço ecumênico que foi pensado para ser o local onde todas as crenças pudessem ser realizadas e o novo Posto de Saúde Santa Luzia, com uma melhor estrutura que o antigo que foi destruído pela enchente e por fim, uns dos espaços mais importantes da comunidade: a Escola Municipal Pedro Pereira da Silva.

\section{A ESCOLA QUILOMBOLA DO MUQUÉM}

De acordo com entrevistas feitas a alguns moradores da comunidade Quilombola Muquém, a Escola de Ensino Municipal Pedro Pereira da Silva tem esse nome porque faz uma homenagem a um antigo quilombola, o senhor Pedro Pereira da Silva. Ele foi um agricultor, nascido em 1907, pai de 10 filhos que doou as terras para a construção da primeira Escola da comunidade. "Seu Pereira", na época, era uns dos representantes da primeira associação dos moradores do Muquém chamada Associação dos Pequenos Produtores do Sítio Muquém, fundada em 1993 quando o prefeito da cidade de União dos Palmares era Iran Menezes que ajudou na construção da Escola.

A escola foi uma das primeiras reivindicações, depois da energia elétrica, pelos moradores do Muquém que por meio da associação buscavam as melhorias para a comunidade. A primeira Escola foi fundada em 13 de outubro de 1993.

A antiga escola era pequena, e tinha apenas uma sala de aula, uma cozinha e um pequeno salão para o lazer, funcionava até o $5^{\circ}$ ano do ensino fundamental, depois que as crianças completavam o $5^{\circ}$ ano iam estudar no povoado Sementeira, vizinho a Comunidade Quilombola Muquém. Por muitos anos foi essa pequena escola existente que supriu os anseios pela educação do povo da referida comunidade, até 


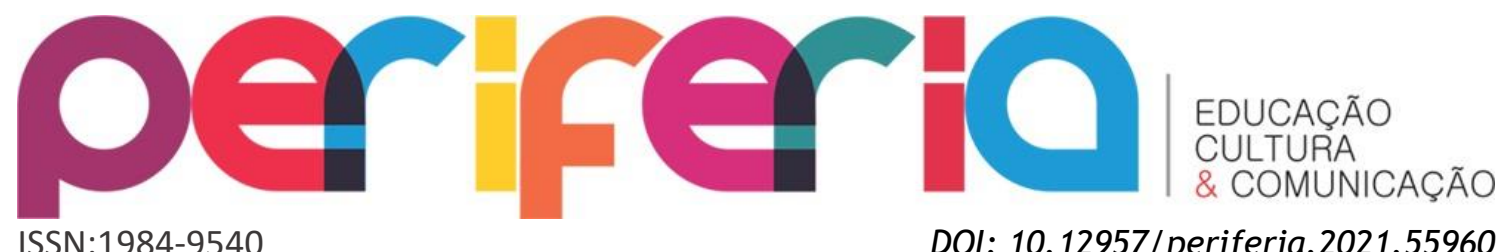

2010 quando a Comunidade sofreu a enchente do Rio Mundaú, arrastando casas, plantações, pessoas e até mesmo a escolinha do Muquém.

Figura 2: Local onde era a instalação da Escola antes da enchente de 2010

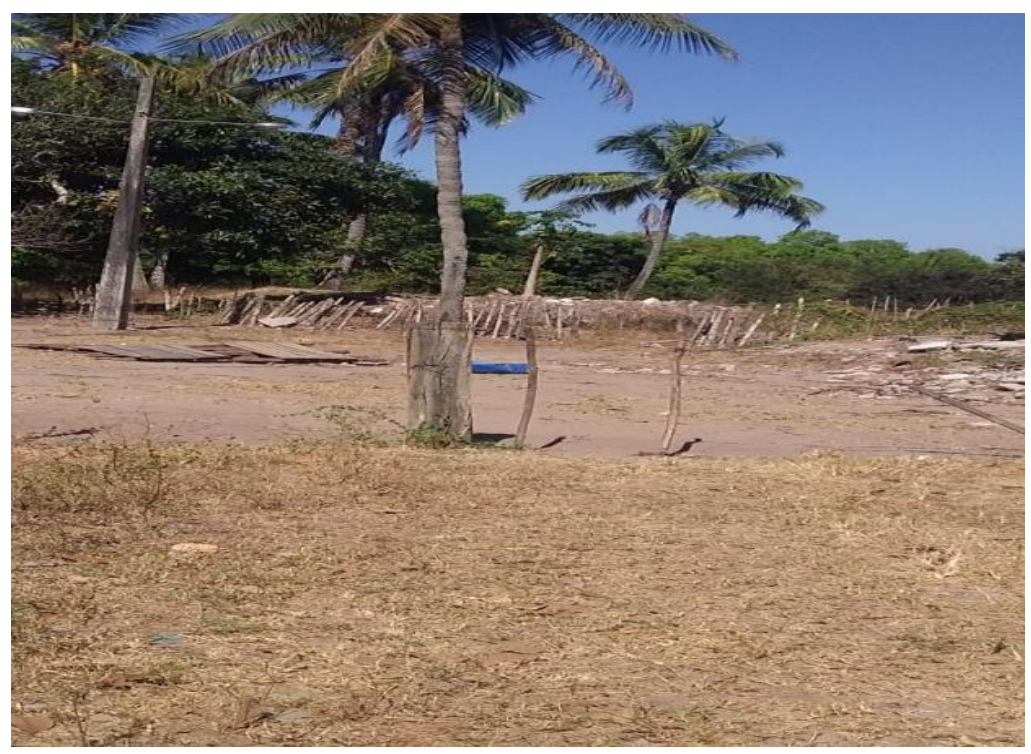

Fonte: Autoras, 2019

\section{RESULTADOS E DISCUSSÕES}

Após a referida enchente surgiu uma nova escola na comunidade, pois a população do Muquém se deslocou para um outro lugar onde hoje se localiza grande parte das casas dos moradores que foram atingidos pelas águas do Rio Mundaú. A nova escola foi inaugurada no dia 13 de outubro de 2013, permanecendo com o mesmo nome, Pedro Pereira da Silva.

A nova escola tem uma estrutura melhor para atender a comunidade e as outras localidades camponesas, localizando-se na Rua Santa Luzia, umas das ruas principais da Comunidade. Quanto à estrutura, a Escola Pedro Pereira possui: sala de direção, sala de almoxarifado, sala de professores, secretaria, sete salas de aula, laboratório de informática, refeitório, dois banheiros para funcionários, quatro banheiros para alunos, biblioteca, sala da criança, além dos espaços de lazer, pátio e horta. 


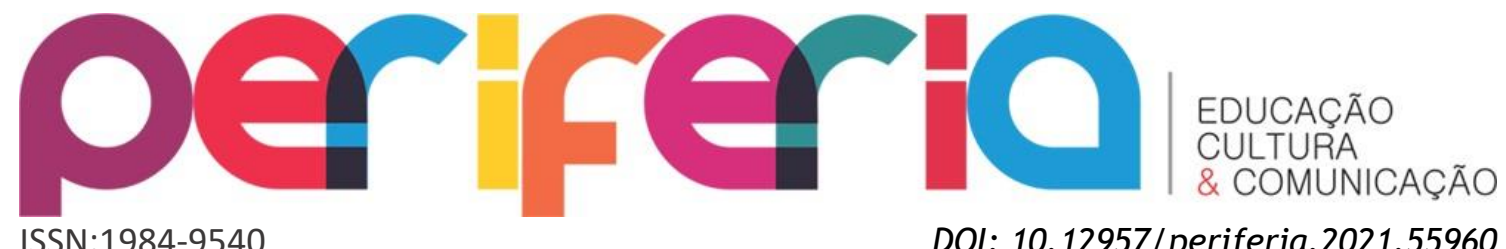

Figura 3- A nova Escola da comunidade Muquém

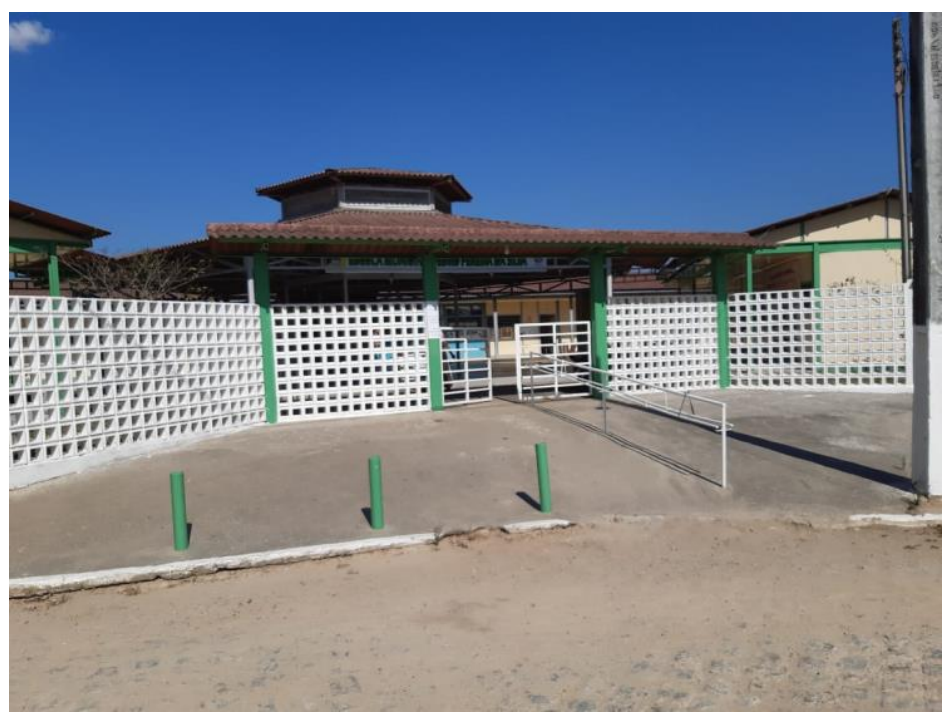

Fonte: Autoras, 2019

A escola da Comunidade tornou-se uma espécie de polo para outros povoados rurais vizinhos do Muquém. De acordo com os questionários aplicados aos alunos dessa escola, a maioria destes é do Muquém, mas há crianças e adolescentes de outros sítios e assentamentos vizinhos que estudam na escola. As crianças que não são da comunidade residem nos assentamentos Santo Antônio da Lavagem, Fazenda e antigo engenho Anhumas, povoado Sementeira, Taquari, sítio Brejo dos Vieiras e Serra da Barriga - no total são 290 alunos, sendo a maioria da própria comunidade quilombola.

A instituição escolar atua nos seguintes níveis de ensino: Educação Infantil, Ensino Fundamental I e II incluindo a modalidade EJA - Educação de jovens e adultos. $\mathrm{Na}$ escola, funcionam os três turnos - manhã, tarde e noite. Só depois dos adolescentes e jovens concluírem o $9^{\circ}$ ano, eles vão estudar na cidade. A Escola também emprega quilombolas como professores e auxiliar de serviços.

De acordo com os questionários aplicados aos alunos da escola da comunidade, mesmo não sendo nascidos no Muquém, alguns se autoafirmam como quilombolas apenas por participar da vida escolar e estudar em uma escola de origem quilombola. Percebemos que mesmo com tantos desafios na educação quilombola e camponesa no Brasil, os alunos afirmaram que gostavam da sua escola em meio a todas as disparidades. Eles a enxergam como uma porta para acesso a um futuro melhor que 


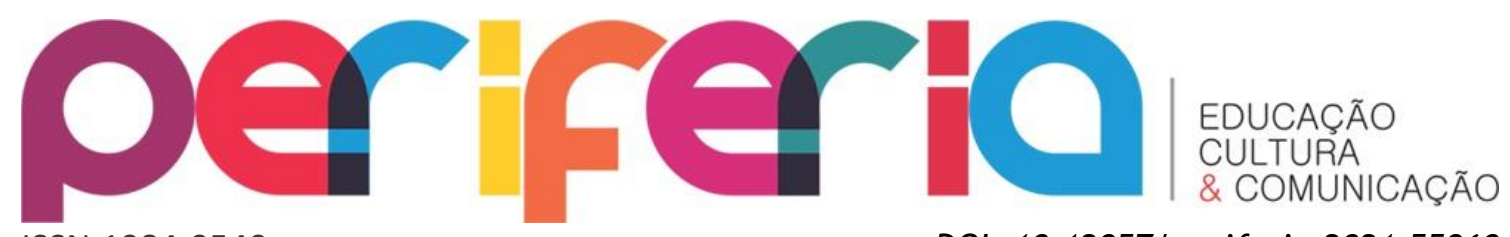

ISSN:1984-9540

DOI: $10.12957 /$ periferia.2021.55960

o dos seus pais que, em sua maioria, são trabalhadores da roça e que não tiveram oportunidade de estudar e mesmo que tivessem, seria necessário o deslocamento diário até a cidade. Hoje com essa escola maior e bem mais estruturada, os alunos veem a possibilidade de uma educação pública como garantia dos seus direitos.

Gráfico 1. Questionário direcionado aos alunos do $6^{\circ} .7^{\circ}$. e $9^{\circ}$ anos.

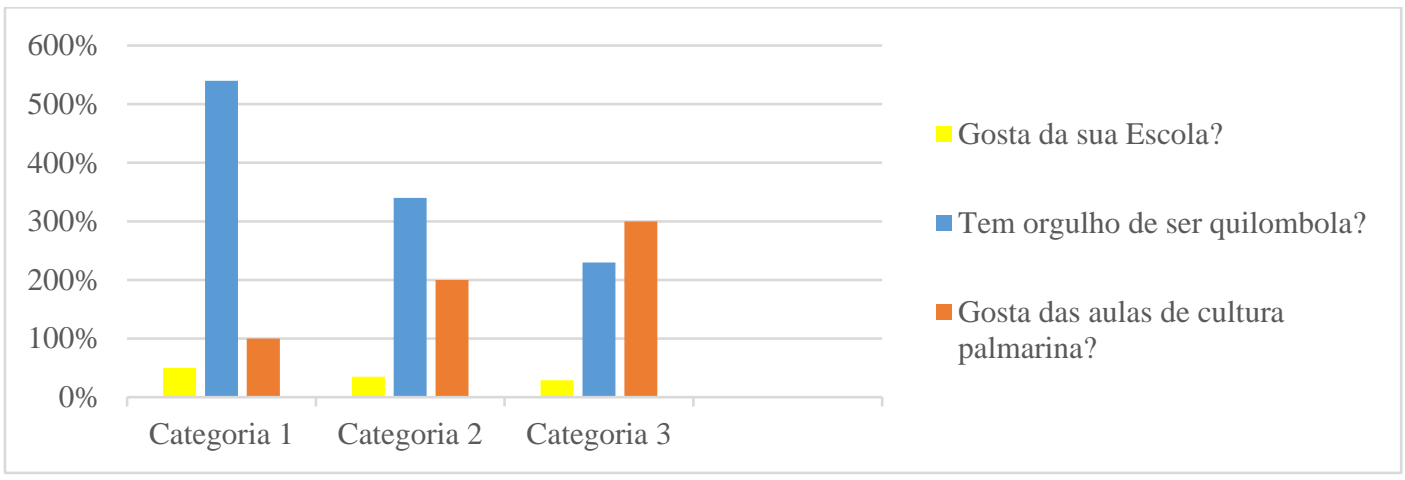

Fonte: AS AUTORAS, 2019

O currículo escolar da comunidade segue a Base Nacional Comum Curricular (BNCC), também trabalha com os temas Transversais dos Parâmetros Curriculares Nacionais (PCNS) com a lei Nacional do $n^{\circ} 10.639 / 2003$ e a lei Municipal de $n^{\circ}$ 994/03 que visa o ensino da cultura palmarina em toda a rede de ensino do município de União dos Palmares (UNIÃO DOS PALMARES, 2003).

Segundo o que diz respeito a educação escolar quilombola ela deve;

Ser desenvolvida em unidade inseridas em suas terras e culturas, requerendo a pedagogia em respeito à especificidade étnico cultural de cada comunidade e formação específica de seu quadro docente observando os princípios constitucionais e a base nacional comum e os valores que integram e orientam a educação básica do Brasil (BRASIL, 2013, p.46).

A Escola Municipal Pedro Pereira da Silva desenvolve projetos voltados para a educação quilombola. Segundo a coordenação pedagógica, todo o plano de ação da escola e o próprio PPP - Plano Político Pedagógico - são voltados para inserção do currículo escolar da lei 1.639/2003 para o plano nacional de implementação das 


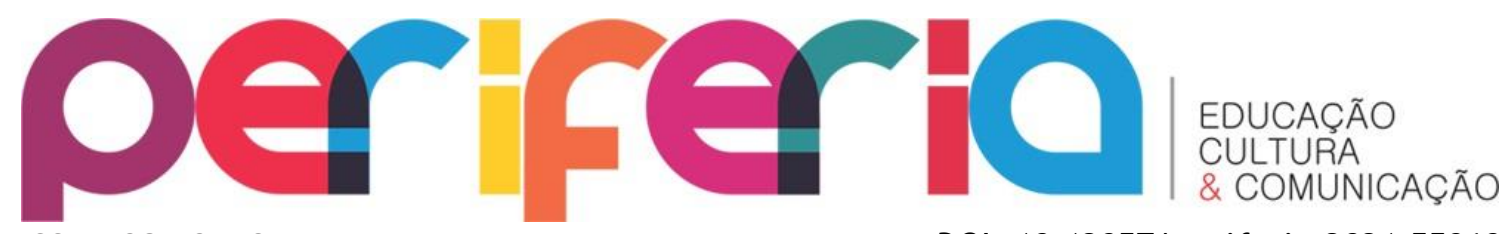

ISSN:1984-9540

DOI: $10.12957 /$ periferia. 2021.55960

diretrizes Curriculares Nacionais e a educação das relações étnico-raciais. Lei essa que vai ao encontro dos artigos $9^{\circ}$ e $11^{\circ}$ do Estatuto da Igualdade Racial promovido pelo Secretaria de Políticas de Promoção da Igualdade Racial (SEPPIR) que traz a importância da população negra, e o direito à participação nas atividades educacionais, conforme disposto nos artigos abaixo:

Art. $9^{\circ}$ A população negra tem direito a participar de atividades educacionais, culturais, esportivas e de lazer adequadas a seus interesses e condições, de modo a contribuir para o patrimônio cultural de sua comunidade e da sociedade brasileira (BRASIL, 2011, p. 14).

Art. $11^{\circ}$ Nos estabelecimentos de ensino fundamental e de ensino médio, público e privado é obrigatório o estudo da história geral da África e da história da população negra no Brasil, observado o disposto na lei $\mathrm{n}^{\circ}$ 9.394, de 20 de dezembro de 1996 (BRASIL, 2011, p. 14).

A lei municipal de $n^{\circ} 994 / 2003$, de 12 de março, que intitula a obrigatoriedade do ensino da cultura negra na sala de aula (UNIÃO DOS PALMARES, 2003), baseada na lei nacional 10.639/2003, trabalha em sua parte diversificada do currículo escolar a disciplina Cultura Palmarina em toda a rede Municipal de ensino de União dos Palmares e na comunidade; além da história da cidade, ensina também a história do povoado quilombola.

O currículo quilombola escolar proposto pelas Diretrizes Curriculares Nacionais da educação básica visa a incorporação dos conhecimentos tradicionais das comunidades quilombolas em articulação com o conhecimento escolar, sem hierarquização. Se faz necessário

[...] organizar um currículo que tenha em sua orientação o desafio de ordenar os conhecimentos e as práticas sociais e culturais, considerando sempre a presença de constelação de saberes que circulam, dialogam e indagam a vida social (BRASIL. 2013, p.462).

É através da lei nacional do ensino da Cultura Afro Brasileira que é norteado o trabalho da Escola Mun. Pedro Pereira da Silva, utilizando dessas diretrizes para uma educação que atenda as peculiaridades da comunidade. Para atender a realidade da história palmarina e quilombola, a câmara de vereadores aprovou em 


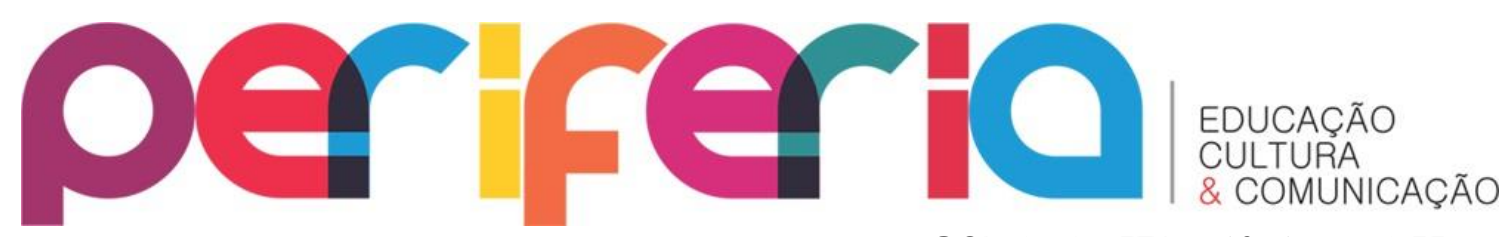

ISSN:1984-9540

DOI: $10.12957 /$ periferia. 2021.55960

2003 a lei municipal ligada a lei nacional onde não apenas iria abordar em sala de aula a história da cultura negra brasileira, mas também a história da cultura palmarina em toda rede de ensino municipal da Cidade de União dos Palmares.

A lei municipal do $n^{\circ}$ 994/03 de 12 de março de 2003 dispõe do estudo e ensino de conteúdos relacionados ao estudo da história do município, incluindo a própria história da Comunidade Muquém (UNIÃO DOS PALMARES, 2003). De acordo com as entrevistas feitas aos gestores da escola, essa lei vem sendo implementada e trabalhada com os alunos da Escola Mun. Pedro Pereira desde 2013, com projetos pedagógicos que abordam a temática negra, indígena e os direitos da cidadania camponesa quilombola.

Foi notório que durante as entrevistas com os moradores da comunidade, uma das problemáticas percebidas foi que hoje muitas crianças da comunidade estão preferindo estudar na cidade, isto é um problema que está crescendo a cada dia, por isso um número tão pequeno na escola da Comunidade. Porém, dos poucos alunos que estudam na comunidade todos disseram gostar do ensino prestado pelos educadores. Segue abaixo um trecho da entrevista realizada com o gestor escolar da comunidade; tal depoimento do mesmo vem apenas a corroborar com o que apresentamos até então sobre a comunidade quilombola e a importância da inserção na escola.

Os principais desafios enfrentados pela escola é envolver a comunidade nas ações da nossa escola, trazendo os pais e filhos para fazer parte do nosso projeto didático, envolver os pais no processo educativo dos filhos, fazê-los entender, pais e filhos, sobre a importância do estudo, conhecimento. Outro desafio é o trabalho de conscientização do significado de ser quilombola e quais as responsabilidades que essa nomenclatura traz para cada um. 0 trabalho de conscientização ainda é muito difícil porque estamos lidando com o senso comum que ainda tem e enfrentamos grandes problemas, tais como: auto-rejeição da cor da pele, do cabelo, da cultura, da história (Depoimento do Gestor 1).

Porém, mesmo com essas adversidades já enraizadas dentro da Comunidade quilombola, a Escola Mun. Pedro Pereira vem realizando, junto a toda comunidade escolar, um significativo trabalho, oferecendo uma educação pública e consciente mesmo dentro das suas limitações e particularidade. 


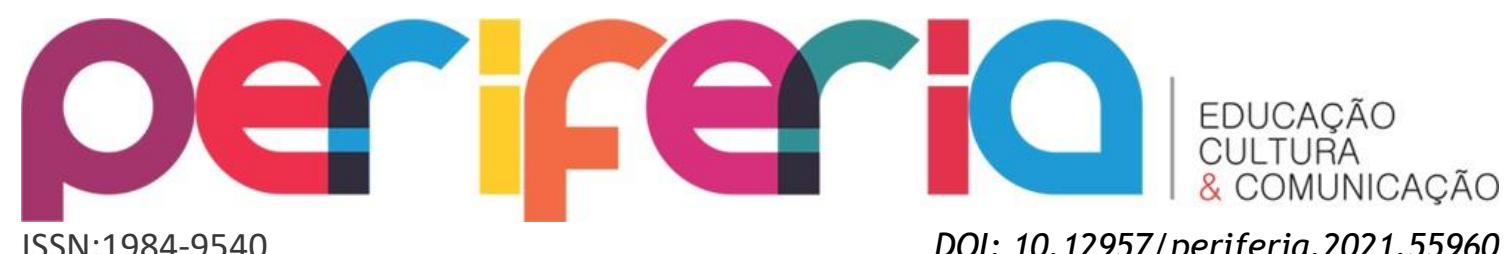

\section{CONSIDERAÇÕES FINAIS}

Dessa forma, consideramos que existe uma precarização do ensino nas escolas públicas brasileiras e quando relacionamos a educação do campo, fazendo um recorte para comunidades de remanescentes de quilombos percebemos que a situação piora, pois a estrutura política e ideológica que se encontra no Brasil hoje não consideram essas comunidades quilombolas e tudo que existe que possa ajudálas está sendo usurpado pelo governo.

0 que nos consiste pensar é que existe possibilidades de estudar e ensinar no campo de acordo com o pensamento de Freire (1987), no qual devemos partir da realidade do educando, ou seja, da realidade do próprio campo - como as características que cada lugar ou território possui e usá-las para o conhecimento. É o que está se desenvolvendo na Comunidade Quilombola Muquém. Uma educação voltada à realidade quilombola, mesmo com as dificuldades e adversidades a Escola Quilombola existe porque foi uma ação dos próprios quilombolas que desejavam e desejam uma educação melhor para seus filhos e netos. E é o trabalho que está sendo feito pelos professores, coordenadores e alunos da escola: trabalhar uma educação voltada para o cotidiano quilombola, se apoiando na lei municipal na propagação da história da cultura palmarina negra e indígena (UNIÃO DOS PALMARES, 2003). Dessa forma mesmo com a existência dos preconceitos sobre a cultura negra, as crianças, adolescentes e jovens estão conhecendo a sua própria história e a do seu povo dentro do ambiente escolar ao qual seus pais não tiveram acesso.

Com a implementação da lei 10.639/2003 e a lei 994/2003 está possibilitando uma grade curricular diferenciada para as crianças da Comunidade Quilombola Muquém (BRASIL, 2003; UNIÃO DOS PALMARES, 2003). É um trabalho de conscientização e a escola tem um papel muito importante, pois é por via da educação que nos tornamos melhores cidadãos capazes de transformar nossa realidade e a do próximo e para isso é necessário que todos tenhamos o direito à educação garantido, assim como os não quilombolas têm acesso, os quilombolas também devem ter esse direito garantido por lei, é um dívida política, jurídica e 


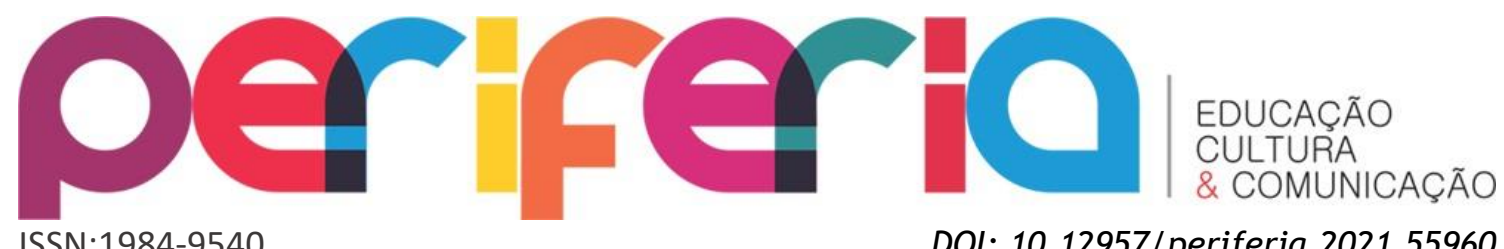

social que a sociedade deve aos quilombolas, pois a perversidade no campo é maior que na cidade.

\section{REFERÊNCIAS}

ALAGOAS. Mapeamento das comunidades quilombolas de Alagoas. Disponível em: http://www.iteral.al.gov.br/dtpaf/comunidades-quilombolas-dealagoas/Mapa\%20das\%20Comunidades\%20Quilombolas2011.JPG/image_view_fullscreen 04/12/19 ás 16h45min.

BRASIL. ECA, CEDECA- Centro de defesa dos direitos da criança e do adolescente. Rio de Janeiro - RJ - Brasil. 1990

BRASIL, Decreto $n^{\circ} 7.352$ de 4 de novembro de 2010. Brasília, 2010.

BRASIL. Diretrizes Curriculares Nacionais Gerais da Educação Básica / Ministério da Educação. Secretaria de Educação Básica. Diretoria de Currículos e Educação Integral. Brasília: MEC, SEB, DICEI, 2013.

BRASIL. Resolução da Lei nacional 10.639. Brasilia, 2003. Disponível em:http://www.planalto.gov.br/ccivil_03/leis/2003//10.639.htm acesso em $10 / 12 / 19$ às $15 \mathrm{~h}$ BRASIL. Base Nacional Comum Curricular. Disponível em: http://basenacionalcomum.mec.gov.br/images/BNCC_EI_EF_110518_versaofinal_si te.pd f acesso em 10/12/19.

BRASIL. SEPPIR- Secretaria de Políticas de Promoção da lgualdade Racial Seppir/PR; Esplanada dos Ministérios, Bloco A, $9^{\circ}$ andar; Brasília- Distrito Federal. 2011.

BEZERRA, Carril, Lourdes de Fátima. Os desafios da educação quilombola no Brasil: 0 território contexto e texto. Revista brasileira de educação, vol.22, $\mathrm{n}^{\circ} 69$, abriljunho, 2017, pp.539-564

CALDART, Roceli, Salete. Educação do campo: Notas para uma análise de percurso. Rio de Janeiro, Junho de 2009.

FREIRE, Paulo. Pedagogia do oprimido. $17^{\mathrm{a}}$ ed. Rio de Janeiro, paz e terra, 1987.

IBGE- Instituto brasileiro de geografia e estatística. União dos Palmares/AL 2010.

KONDER, L. O que é dialética. São Paulo: Brasiliense, 2004.

MACHADO, L.C.T. Da educação rural à educação do campo: conceituação e problematização. VI Seminário Internacional sobre Profissionalização Docente. 


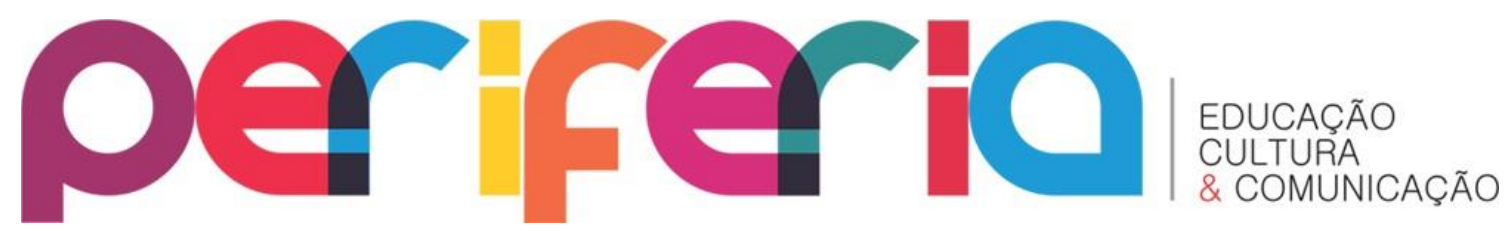

ISSN:1984-9540

DOI: $10.12957 /$ periferia. 2021.55960

MOREIRA, Luciano; MACENO, Talvanes. Educação, reprodução social e crise estrutural do capital. in BERTOLDO, Edna; MOREIRA, Luciano Accioly; JIMENSE, susana. Trabalho, educação e formação humana: a necessidade histórica da revolução. São Paulo: Instituto Lu'kascs, 2012.

PRODANOV, C. C.; FREITAS, E.C. Metodologia do trabalho cientifico: Método e técnicas da pesquisa e do trabalho acadêmico. 2.ed. Novo Hamurgo: Feevale, 2013.

REIS, Alexandro Anunciação. Cartilha Comunidades quilombolas no processo de licenciamento ambiental/ Alexandro Anunciação Reis. Brasília; Fundação Cultural Palmares; 2014.

SANTOS, Milton. As cidadanias Mutiladas. São Paulo- Imprensa Oficial do Estado. 1997.

SANTOS, Milton. A Natureza do Espaço: técnica e tempo, razão e emoção. São Paulo: Hucitec, 2012.

SANTOS, Milton. O Espaço do Cidadão. 7. ed., 2. reimpr. - São Paulo: Editora da Universidade de São Paulo, 2014.

UNIÃO DOS PALMARES. Resolução da Lei municipal no 994/03 de 12 de março de 2003. Disponível em: Câmara municipal dos vereadores de União dos Palmares -Al. Fevereiro de 2019. 